\title{
Injury talk: spontaneous parent-child conversations in the aftermath of a potentially traumatic event
}

\author{
Eva Alisic, ${ }^{1,2,3}$ Shaminka Gunaratnam, ${ }^{1,2,4}$ Anna Barrett, ${ }^{1}$ Rowena Conroy, ${ }^{2,5,6}$ Helen Jowett, ${ }_{1}^{6}$ \\ Silvia Bressan, ${ }^{2,7}$ Franz E Babl, ${ }^{2,6,8}$ Roderick McClure, ${ }^{9}$ Vicki Anderson, ${ }^{2,5,6}$ Matthias R Mehl ${ }^{10}$
}

\begin{abstract}
${ }^{1}$ Monash University Accident Research Centre, Monash University, Melbourne, Victoria, Australia; ${ }^{2}$ Murdoch Children's Research Institute, Melbourne, Victoria, Australia; ${ }^{3}$ Department of Psychosomatics and Psychiatry, University Children's Hospital Zurich, Zurich, Switzerland; ${ }^{4}$ School of Psychological Sciences, Monash University, Melbourne, Victoria, Australia; ${ }^{5}$ Melbourne School of Psychological Sciences, University of Melbourne, Melbourne, Victoria, Australia; ${ }^{6}$ The Royal Children's Hospital, Melbourne, Victoria, Australia; ${ }^{7}$ Department of Women's and Children's Health, University of Padova, Padova, Italy; ${ }^{8}$ Department of Paediatrics, University of Melbourne, Melbourne, Victoria, Australia; ${ }^{9}$ Harvard Injury Control Research Center, Harvard School of Public Health, Boston, Massachusetts, USA; ${ }^{10}$ Department of Psychology, University of Arizona, Tucson, Arizona, USA

Correspondence to Dr Eva Alisic, Monash University Accident Research Centre, 21 Alliance Lane, Monash University, Melbourne, VIC 3800, Australia; eva.alisic@monash.edu
\end{abstract}

\begin{abstract}
Background While talking about traumatic experiences is considered central to psychological recovery, little is known about how these conversations occur in daily life.

Objective We investigated spontaneous injury talk among parents and children in the aftermath of a child's hospitalisation due to physical trauma, and its relationship with children's socioemotional functioning.

Methods In a prospective naturalistic observation study, we audio-sampled the daily life of 71 families with the Electronically Activated Recorder after their child (3-16 years old) was discharged from hospital. We collected close to 20000 snippets of audio information, which were double-coded for conversation characteristics, and measured children's socioemotional functioning with the Strengths and Difficulties Questionnaire (SDO) at 6 weeks and 3 months postinjury.

Findings The children were involved in injury talk for, on average, $46 \mathrm{~min} /$ day, $9 \mathrm{~min}$ of which referred to emotions. Children had significantly more injury conversations with their mothers than with their fathers. The tone of injury conversations was significantly more positive than that of non-injury conversations. More direct injury talk was associated with fewer problems on the emotion subscale of the SDO at 3 months. Other associations between aspects of injury talk and children's socioemotional functioning were mostly non-significant, although they appeared to be stronger at 3 months than at 6 weeks.
\end{abstract}

Conclusions Families spontaneously talked about the injury and associated issues for about the same amount of time per day as a therapist might within a session (a 'therapy hour').

Clinical implications Making full use of naturally occurring injury talk may be a valuable direction for parent and family-focused postinjury interventions. However, the study design prevents causal inference, and further exploration is warranted.

\section{BACKGROUND}

The consequences of injuries in childhood can go beyond physical health. While most children recover well, a minority experience long-term distress, impairing functioning and development. ${ }^{1}$ In particular, children admitted to hospital after injury are at risk of mental health problems (eg, post-traumatic stress or depressive symptoms), academic underperformance and social difficulties. ${ }^{2}$

Parents are central support figures after a child's injury and key conversation partners when children process their experiences. Parents can help children to express, clarify and accept experiences, and correct misinformation. ${ }^{3-5}$ An emerging body of experimental research suggests that children benefit from adults' capacity to model appraisals and meaning-making, and to develop a shared narrative. ${ }^{6-8}$ Parents' specific approach to these conversations might also make a difference, for example, the degree to which they elaborate or talk about emotions. ${ }^{910}$

While family research often makes use of elicited narratives, ${ }^{11-13}$ we are unaware of any studies of spontaneous conversations in the home after a potentially traumatic event, without researchers present. Therefore, this is the focus of our research. A better understanding of natural injury talk-when, how and with whom it occurs-and its relationship with children's mental health and well-being outcomes may identify important opportunities to optimise children's recovery.

Capturing daily life in a reliable and non-intrusive way is difficult. The Electronically Activated Recorder (EAR) ${ }^{14-17}$ offers a promising method, capturing behaviour in real time via audio recording. It functions on a small mobile device, such as an iPod, and intermittently samples snippets of ambient sounds. Participants find the EAR unobtrusive, while data collected over a short amount of time provide reliable estimates of usual social behaviour. ${ }^{15}$ One of the important advantages of the method is that it does not listen in on full conversations, but, in sampling short sound bites, acquires just enough information to assess the nature of the interactions. The EAR has been used successfully to study sensitive topics with adults, such as daily life in the context of coping with cancer ${ }^{18}$ and in the acute aftermath of 11 September $2001 .{ }^{19} \mathrm{~A}$ few studies have used the EAR with children, including in the context of health research. ${ }^{20-24}$ The EAR has specific advantages for child research: it does not require the capacity to read or understand questions posed in questionnaires or to maintain attention during interviews. ${ }^{25}$ Likewise, it does not rely on retrospective accounts of behaviour.

\section{OBJECTIVE}

We aimed to investigate the nature of injury talk in the aftermath of a child's hospitalisation due to physical trauma, by means of an EAR study in 3 to 16-year-old children and their families. In this article, we focus on two questions:

1. What are the characteristics of injury talk in children's daily life?

2. How do injury talk characteristics relate to children's subsequent well-being?

For the first question, we focus on the frequency of injury talk in daily life, children's conversation partners and the emotional tone of the injury conversations. For the second question, we explore relationships between these injury talk characteristics and children's subsequent 


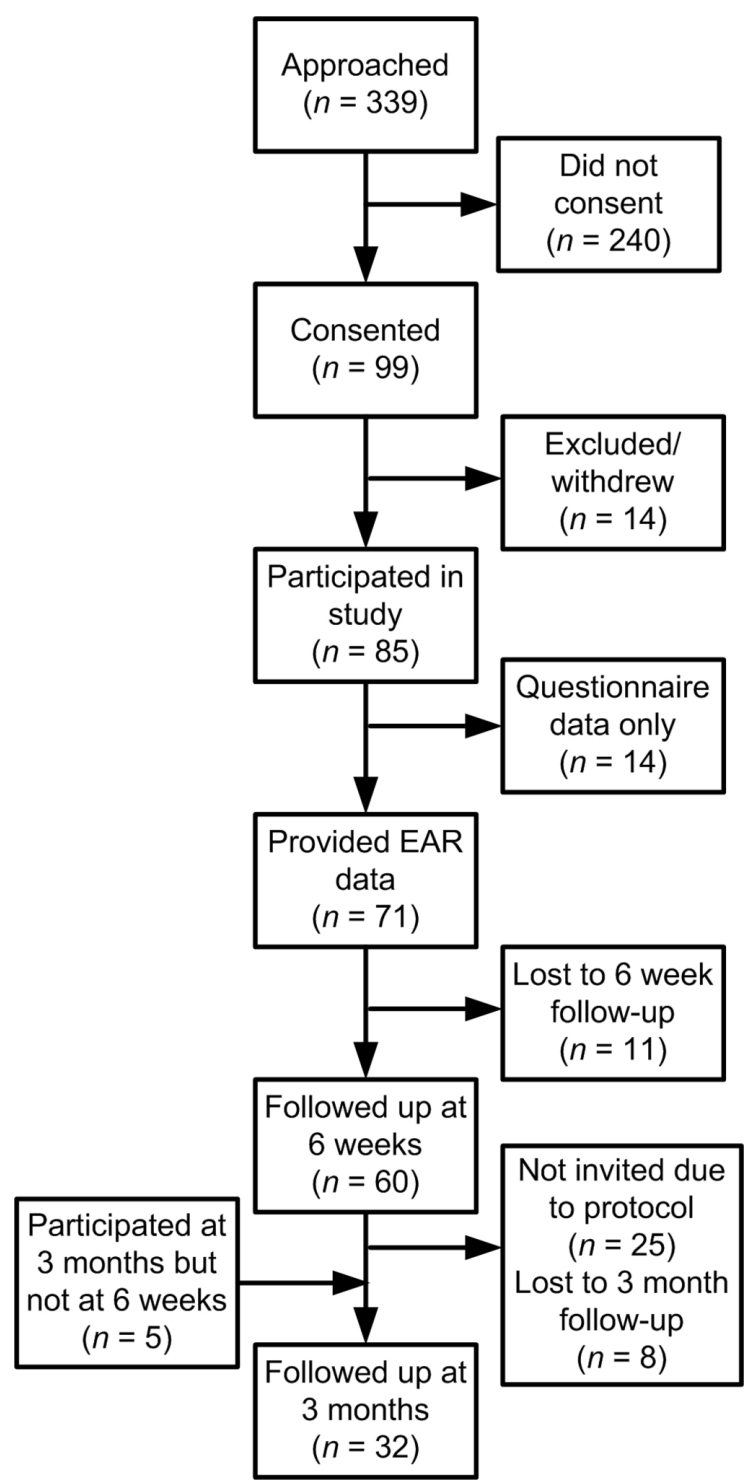

Figure 1 Recruitment flowchart. EAR, Electronically Activated Recorder.

socioemotional functioning. Given the novelty of our method, no a priori hypotheses were made.

\section{METHODS}

This study is part of the Ear for Recovery project, a prospective observational study among injured children aged 3-16 years and their families. The full study protocol is provided in Alisic et al. ${ }^{16}$

\section{Participants}

\section{Eligibility and recruitment}

Participants were children who had sustained an injury that resulted in a stay of at least 24 hours at the Royal Children's Hospital, Melbourne, Australia, and their families. Children were ineligible if the injury was thought to be intentional, if they arrived at the hospital with a Glasgow Coma Scale ${ }^{26}$ score below 9 (ie, indicating severe acquired brain injury), if their hospital stay exceeded 4 weeks, or if the injury was secondary to another medical disorder, since these might not represent typical postinjury interactions after discharge.

Families were approached during their child's hospital admission based on information obtained from the hospital trauma registry in consultation with hospital staff. As depicted in figure 1, 339 families were approached for participation, of which 99 (29\%) consented. Fourteen families did not participate after consenting; they reported feeling too stressed at the time of the planned data collection, could not be contacted after discharge, or experienced an additional traumatic event. Due to equipment malfunction in the initial phase of the project and a few families eventually opting for questionnaire participation only, we retained 71 families $(21 \%$ of the approached families) with useable EAR data. This is in line with recruitment rates of previous paediatric traumatic stress studies focused on family functioning. ${ }^{827}$ Following baseline assessment, 60 families $(84.5 \%$ of the sample) proceeded to follow-up at 6 weeks. Initially, this was the end of our data collection; we later included a 3-month follow-up in the protocol. Of the 35 families invited for follow-up at 3 months postdischarge, 27 (77.1\% of those invited) were retained and an additional 5 families completed the 3-month phone interview despite not being contactable at the 6 -week mark ( 3 months $n=32,45.1 \%$ of total sample).

\section{Demographic information}

On average, the 71 child participants (59.2\% male) were 10.4 years old $(S D=3.6$ years, range $3-16$ years) at the time of their injury. All children except two were born in Australia. The majority of children $(n=59$, 83.1\%) lived in two-parent families, three of which with one stepparent. Eleven lived in single-parent households (15.5\%), and one had another living arrangement. Overall, 69 female and 63 male caregivers were involved, whom we refer to as mothers and fathers for ease of reading. On average, the families lived $85.4 \mathrm{~km}$ from the hospital $(S D=101.2 \mathrm{~km}$, range $=3-552 \mathrm{~km}$ ). In terms of socioeconomic status (SES), our sample had a mean Index of Relative Socioeconomic Disadvantage of 1017.6 $(S D=54.6$, range $=880.5-1117.4$, based on participants' postcodes), not significantly different from the Australian population mean $(M=1000$, $\mathrm{SD}=100)^{28}$

Most children had sustained fractures or orthopaedic injuries (see table 1), due to sports incidents, falls or traffic crashes. The majority spent between 1 and 3 days in hospital $(n=53,74.6 \%)$, while 17 children (24.0\%) were hospitalised for 4-10 days, and 1 child for 17 days. Injury Severity Scores (ISS) ${ }^{29} 30$ ranged from mild to profound, with most in the mild and moderate categories $(M=7.1, S D=6.2)$.

Table 1 Child injury characteristics

\begin{tabular}{lc}
\hline & Frequency (\%) \\
\hline Injury type $^{*}$ & $33(46.5)$ \\
\hline Fractures/orthopaedic & $13(18.3)$ \\
\hline Head injuries & $11(15.5)$ \\
\hline Soft tissue injuries & $9(12.7)$ \\
\hline Multiple traumas & $5(7.0)$ \\
\hline Other & \\
\hline Context of injury & $24(33.8)$ \\
\hline Sports and recreation & $21(29.6)$ \\
Falls & $20(28.2)$ \\
\hline Motor vehicle accidents & $6(8.5)$ \\
\hline Other & \\
\hline Injury Severity Score (ISS) $\dagger$ & $48(67.6)$ \\
\hline $1-8$ (mild) & $18(25.4)$ \\
\hline $9-15$ (moderate) & $2(2.8)$ \\
$16-24$ (severe) & $3(4.2)$ \\
\hline $25+$ (profound) & \\
\hline 71. & \\
\hline
\end{tabular}

$\mathrm{n}=71$.

* One child had a skull fracture, which was counted as a head injury.

tScores on the ISS range from 0 to 75 , with severity ratings applied according to Bolorunduro et al. ${ }^{30}$ 


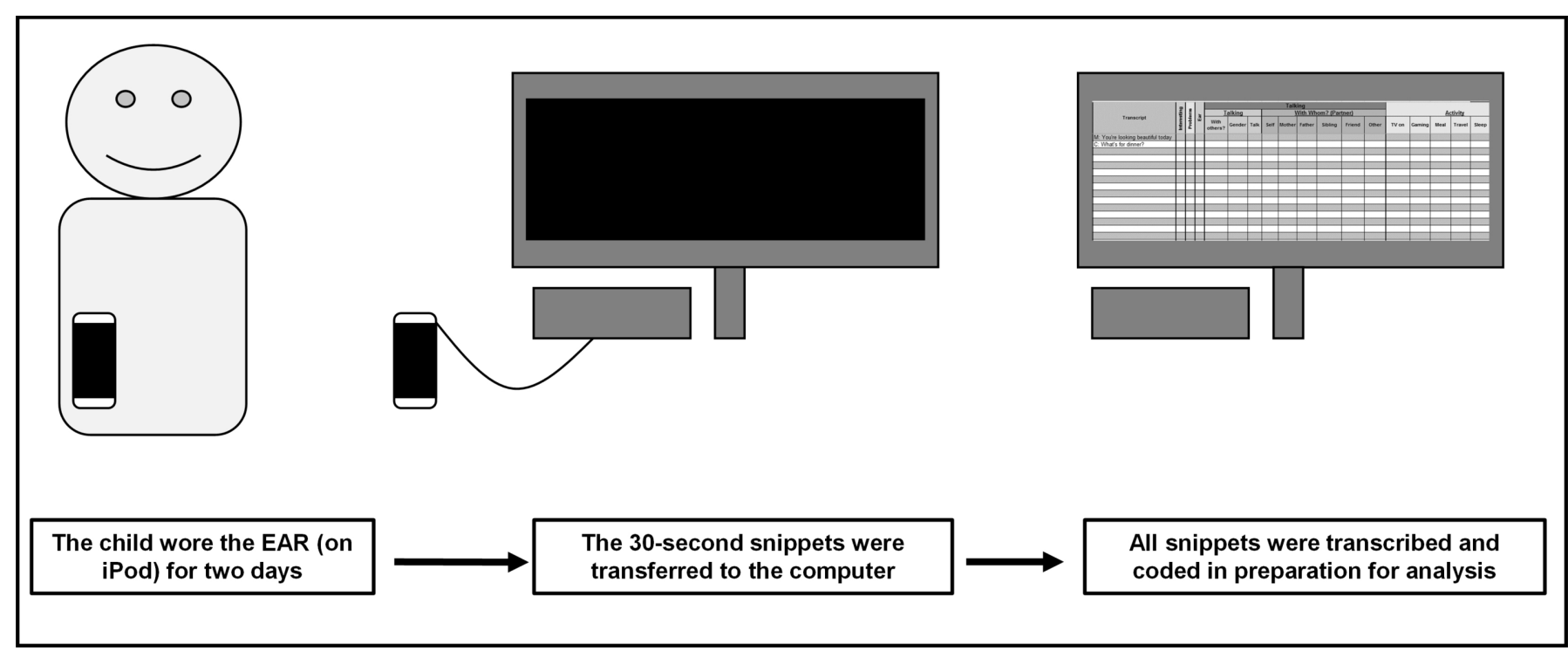

Figure 2 Brief overview of the EAR data collection process. EAR, Electronically Activated Recorder.

There were no significant differences in age, sex, SES or injury severity between the children who continued to 6-week follow-up and those who did not, or between the children who continued to 3-month follow-up and those who did not. Similarly, there were no significant differences in these variables between those who only participated at 6 weeks and those who participated at 3 months. However, those who continued to any follow-up (at 6 weeks, 3 months or both) had significantly higher ISS than those who did not (mean difference $=3.07, t(68.94)=3.70, p<0.001$ ), with no other significant differences in age, sex or SES. Participants with lower scores on the SDQ at 6 weeks were more likely to participate at 3 months (mean difference $=3.68, t(58)=2.54, p=0.014$ ).

\section{Measures \\ The EAR}

The children wore the EAR in a protective elastic belt during 2 consecutive days in which the child was at home/with the family, such as a weekend, public holiday or school holiday, within a month after the injury (see also figure 2). We used the iEAR app ${ }^{17}$ on Apple iPod Touch devices that were loaned to the families. Because we were interested in behaviours that were potentially low frequency, we recorded a 30 s snippet every 5 min. The study yielded a total of 19407 snippets of $30 \mathrm{~s}(\mathrm{M}=273.3$ snippets per family, $S D=84.9$ ). The families kept a simple diary to identify the child's activities, who they were with and any moments that the EAR was not worn by the child. Compliance was good: $90.7 \%$ of the snippets were valid, indicating that the participant wore the device when requested, in line with the compliance rate of a recent study on couples' conversations about cancer $(85 \%) .{ }^{18}$ On average, $1.0 \%(S D=1.1 \%$, range $=0 \%-5 \%)$ of wake time snippets mentioned the EAR or the study, indicating low obtrusiveness.

\section{Child socioemotional functioning}

We measured children's socioemotional functioning via the parent-reported Strengths and Difficulties Questionnaire (SDQ). ${ }^{31}$ The SDO is a brief behavioural screening questionnaire for 3-17 year-olds that is widely used in healthcare settings. It provides scores for emotional problems, conduct problems, hyperactivity, peer problems and prosocial behaviour (the total score includes the first four of these subscales). The reliability and validity of the SDQ have been shown to be adequate. ${ }^{31}{ }^{32}$ We used the Australian age-adapted versions (for 3-year-olds; $4-10$ year-olds; and 11-17 year-olds). For the other child well-being outcomes described in the study protocol ${ }^{16}$ (eg, the child-reported Children's Revised Impact of Event Scale, ${ }^{33}$ and the Child Post-traumatic Stress Scale ${ }^{34}$ ) we had data only for small subsamples of children of 8 years and older. Because the SDO data were available for all age groups, we used it as our main measure for the current article.

\section{Procedure}

\section{EAR transcription and coding}

All sound files were transcribed and coded by two independent coders. An overview of the coding is available in the protocol ${ }^{16}$ and in the coding manual available via the first author. We focused on children's interaction partners, injury talk and tone of the conversations. Regarding interaction partners, we coded for each file whether the child was alone or not, and in case of the latter, whether the child was interacting with one or more people, or near to other people but not interacting (eg, when adults were talking among themselves). When the child was interacting with one or more people, we coded their role (eg, mother, father, sibling). A snippet was considered 'injury talk' when it referred to the injury, either directly or indirectly. Direct injury talk involved mentions of the injury or the event that caused the injury (eg, memories of the event, descriptions of the wound, complaining about pain). Indirect injury conversations included those that would not have happened if not for the injury (eg, discussing reactions at school: 'I've got a lot of advantages at school now... well I got away with my homework'). Within injury conversations, a conversation was considered 'emotion talk' when any speaker shared his/her own personal emotions or feelings. Finally, we coded the overall tone of a snippet, as well as the tone for each speaker within the snippet, on a rating scale from 'very negative' (1) to 'very positive' (7), with 4 being neutral. Child tone, mother tone and father tone were evaluated only in conversations where they actually spoke.

Once all snippets were transcribed and double-coded in spreadsheet format, 'problem' snippets (ie, those where there was evidence from audio data or the diary that the participant was not wearing the device or there were significant recording issues), as well as those in which the child was asleep during the recording hours, were removed from further analyses ( $9.3 \%$ of snippets).

\section{Statistical analyses}

We converted the codes in the master spreadsheet to a Statistical Package for the Social Sciences (SPSS) V.23 file, which was restructured and aggregated by participant ID and coder in order to evaluate inter-rater reliability. In line with past EAR studies, we calculated one-way random 
Table 2 Themes in injury talk

\begin{tabular}{|c|c|c|}
\hline Theme & Description & Example of verbatim transcript ${ }^{*}$ \\
\hline Details of the event & $\begin{array}{l}\text { A recount/discussion of the event that caused the } \\
\text { injury }\end{array}$ & $\begin{array}{l}\text { AM: Oh (Child's name)'s all grown up. Oh my goodness oh what have you done? } \\
\text { C: Had to go to hospital ... because I fell over the top of my horse's head... } \\
\text { AM: Ah. } \\
\text { F: Face planted.... } \\
\text { AM: Goodness me. } \\
\text { F: Ended up a couple of days at the Children's. About a week off school. } \\
\text { C: Two nights, three days. } \\
\text { F: And another half day next week. Maybe another four weeks. } \\
\text { AM: Oh my goodness. }\end{array}$ \\
\hline Pain & Verbal expressions of pain or discomfort & $\begin{array}{l}\text { C: I accidentally pulled a bit off and now my hand is stinging a lot. Um it has got two plates it's } \\
\text { really sore. }\end{array}$ \\
\hline Practical needs & $\begin{array}{l}\text { Interactions surrounding changing of dressings, } \\
\text { requesting food or drink, or the need for a shower }\end{array}$ & $\begin{array}{l}\text { C: Excuse me mum I know you're doing that but can you get me a glass of water please? } \\
\text { M: Yep. } \\
\text { C: Thank you. }\end{array}$ \\
\hline Being careful & Some children were warned against future injury. & $\begin{array}{l}\text { C: Hey! Hop on your motorbike! What? } \\
\text { M: You're on your last warning on that bike okay? } \\
\text { C: Okay. } \\
\text { M: You understand? Mummy's just really worried that only a week ago... You've got to look } \\
\text { after yourself alright? I know it's just a baby's balance bike but still, you've got to be careful. }\end{array}$ \\
\hline Missing out & $\begin{array}{l}\text { Some children expressed disappointment at } \\
\text { restrictions from their injury. }\end{array}$ & $\begin{array}{l}\text { C: Do some running and maybe do some jogging you can do all the activities and you can } \\
\text { get it wet. Okay? Okay? Let's think that. Especially that I can get it wet. Cause they're going } \\
\text { swimming. } \\
\text { M: I know } \\
\text { C: They're going swimming mum. } \\
\text { M: I know } \\
\text { C: That's so not fair. You know I love swimming. Its not fair. How come I have to miss out on } \\
\text { all the good stuff? }\end{array}$ \\
\hline
\end{tabular}

* Minor details removed for confidentiality.

$A M$, adult male (not father); $C$, child; $F$, father; $M$, mother.

intraclass correlations (ICC [1,2]) for the average measure. ${ }^{35}$ The ICCs in the current study all indicated adequate intercoder agreement (ICC $>0.7$, $\left.I C C_{\text {range }}=0.75-0.96\right)$.

The master SPSS file was subsequently aggregated by participant ID to obtain one average value per participant for each coding category across valid snippets. We calculated means, SD and ranges to describe family interactions. Descriptive data were presented as a percentage of children's time awake or of their (injury) interactions, and labelled accordingly. We also translated percentages to the equivalent absolute time in a typical day in which a child is awake for 15 hours. ${ }^{36}$ We converted tone from a seven-point scale to the corresponding percent of maximum possible (POMP) score to aid interpretation (range $=0 \%-100 \%$, with higher scores indicating a more positive tone). ${ }^{37}$ The alpha level was set at .05 . We ran paired samples t-tests (robust when $n>30$ ) ${ }^{38}$ to compare mother and father interactions, as well as amount of emotion talk and tone of talk in injury-related versus non-injury-related conversations. We used two-tailed Spearman's correlations to explore associations with children's well-being, ${ }^{39}$ since there was a positive skew in most EAR variables (we opted not to transform the variables to facilitate interpretation).

\section{FINDINGS}

\section{Characteristics of injury talk in children's everyday life}

On average, $46.8 \%$ (SD=18.0\%) of children's recorded wake time involved interactions with other people. Of these interaction snippets, $11.0 \%$ were injury related $(S D=13.2 \%$, median $=6.5 \%$, range $=0 \%-65.0 \%)$. In terms of wake time, injury talk ranged from $0 \%$ to $26 \%$ of the day (ie, average $5.0 \%$ of wake time recordings). In a 15 -hour day this corresponds to an estimated average of 46 min of 'injury talk'. Table 2 highlights common themes in injury talk, including references to what happened, pain, practical needs, being cautious and missing out.

About $42.5 \%$ of the injury talk was directly referring to the injury or the event that caused it, while $57.5 \%$ referred to it indirectly (eg, a mother made sure her 15-year-old son sat comfortably and then suggested washing his hair). Approximately $20.2 \%$ of the injury talk referred to emotions, corresponding to an estimated 9 min in a typical day. Injury-related conversations were significantly more likely to reference emotion than other conversations ( $20.2 \%$ vs $10.2 \%$; when considering only families who had injury conversations $t(67)$ was $4.36, p<0.001)$.

Children's conversations about the injury involved their mothers (on average $53.8 \%$ of injury talk), fathers (24.3\% of injury talk), siblings (29.3\% of injury talk) and others (youth $18.8 \%$, adults $22.5 \%$; note that these add up to over $100 \%$ due to group conversations). In two-parent families ( $n=59)$, mothers talked significantly more about the injury with their children than fathers: $6.5 \%$ vs $2.8 \%$ of interactions (or $2.9 \%$ vs $1.2 \%$ of wake time), corresponding to $26 \mathrm{~min}$ vs $10 \mathrm{~min}$ in a 15 -hour day $(t(58)=62, p=0.001)$. The pattern also occurred in the total sample and in two-parent families in which both parents were present in the home during the recording.

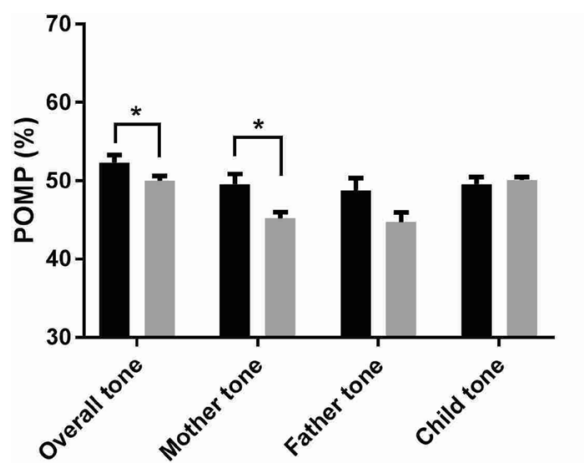

Injury-related Not injury-related

Figure 3 Comparing tone in injury-related and other conversations. POMP, percent of maximum possible score. 


\begin{tabular}{lcccc}
\hline \multirow{4}{*}{ Table 3} & \multicolumn{5}{c}{ Spearman's correlations with child demographic variables } \\
\hline & Age & Sex & ISS & SES \\
\hline Injury talk & 0.14 & 0.03 & -0.09 & 0.07 \\
Direct injury talk & 0.10 & -0.11 & -0.12 & -0.01 \\
Indirect injury talk & 0.09 & 0.08 & -0.07 & 0.11 \\
Overall injury talk tone & 0.02 & 0.00 & 0.08 & 0.08 \\
Mother injury talk tone & -0.18 & -0.04 & -0.19 & 0.12 \\
Father injury talk tone & -0.21 & 0.01 & 0.28 & 0.24 \\
\hline
\end{tabular}

$\mathrm{N}$ ranged from 29 to 71.

Sex: male $=0$, female $=1$. (Direct/indirect) injury talk is depicted as a percentage of wake time.

${ }^{*} \mathrm{p}<0.05$.

ISS, Injury Severity Score; SES, socioeconomic status, measured by the Index of Relative Socioeconomic Disadvantage.

Figure 3 shows the average tone in injury-related conversations and other conversations, expressed in percentage of the maximum possible score. Overall tone was rated as more positive in injury conversations compared with non-injury-related conversations $(t(67)=3.23, p=0.002$, $d=0.39$ ). Mothers' utterances had a more positive tone in injury conversations compared with non-injury conversations $(t(61)=3.24, p=0.002$, $d=0.41$ ). Children and fathers did not show this difference. For injury conversations in two-parent families, mothers' tone was significantly more positive than fathers' tone $(t(40)=2.09, p=0.043, d=0.33)$. For non-injury talk, they did not differ. Further details are available in the online supplementary file.

The amount of injury talk — overall injury talk, as well as direct and indirect injury talk separately —-was not associated with children's age, sex, SES or injury severity. The same was found for the tone of the conversations; overall tone, mothers' tone and fathers' tone in injury conversations were not related to the child's age, sex, SES or injury severity (see table 3).

\section{Relationships with children's socioemotional functioning}

At 6 weeks after the injury, on average, parents rated their child's socioemotional functioning on the SDO as within the normal range (total score; $M=9.62, S D=5.84$; range $0-25 ; n=60$; see table 4). For 15 children (25\%), however, parents rated their children's behaviour in the borderline or 'abnormal' categories.

Children's well-being at 6 weeks postinjury was not associated with the amount of injury talk (either overall, direct or indirect) or with the tone of the injury conversations (overall or by either parent). Only the amounts

Table 4 Average rated child socioemotional functioning at 6 weeks and 3 months

\begin{tabular}{lllcll}
\hline Variable & Time point & Min & Max & M & SD \\
\hline SD0 emotional problems & 6 weeks & 0 & 9 & 2.43 & 2.34 \\
SD0 conduct problems & 6 weeks & 0 & 8 & 1.77 & 1.71 \\
SDQ hyperactivity & 6 weeks & 0 & 10 & 3.82 & 2.58 \\
SD0 peer problems & 6 weeks & 0 & 6 & 1.60 & 1.66 \\
\hline SDQ prosocial behaviour & 6 weeks & 4 & 10 & 8.07 & 1.60 \\
\hline SDQ emotional problems & 3 months & 0 & 6 & 1.81 & 2.04 \\
\hline SDQ conduct problems & 3 months & 0 & 7 & 1.63 & 1.72 \\
\hline SDQ hyperactivity & 3 months & 0 & 10 & 3.38 & 2.56 \\
\hline SDQ peer problems & 3 months & 0 & 4 & 1.06 & 1.22 \\
\hline SDQ prosocial behaviour & 3 months & 3 & 10 & 8.19 & 1.84 \\
\hline SCODS are from
\end{tabular}

Scores are from subscales of the Strengths and Difficulties Questionnaire (SDQ). $\mathrm{n}=60$ at 6 weeks and $\mathrm{n}=32$ at 3 months. of direct injury talk with both mothers and fathers were associated with higher scores on the prosocial behaviour scale (see table 5).

For the subset of 32 families who were interviewed by phone at 3 months postinjury, the children's SD0 total scores were 7.59 (SD $=5.21$, $\mathrm{n}=27)$ at 6 weeks and $7.88(\mathrm{SD}=5.56)$ at 3 months postinjury, respectively, with six children (18\%) scoring in the borderline or 'abnormal' categories at 3 months.

The associations between injury talk and child socioemotional functioning at 3 months appeared to be stronger than at 6 weeks, although many were non-significant (note that this was a subsample of $n=32$; see tables 4 and 6). More total and indirect injury talk with father was associated with lower levels of conduct problems at 3 months, and injury talk had various associations with lower levels of peer problems and higher levels of prosocial behaviour. Notable is the negative relationship between direct injury talk and emotional problems at 3 months; a larger amount of direct talk about the injury in the direct aftermath of hospitalisation was related to a lower score on emotional problems.

\section{DISCUSSION}

The current study provided novel insights into naturally occurring injury talk after a child's discharge from the hospital. We made use of daily life observations with the EAR methodology and found that families spontaneously talked about the injury, its causes, or its consequences for an estimated average of $46 \mathrm{~min} /$ day. This included very 'practical' talk as well as recounts of what happened and conversations about emotions associated with the injury. The study showed that conducting EAR research with children in the aftermath of a potentially traumatic experience is feasible: compliance with the study procedures was good, and obtrusiveness appeared to be low, in line with earlier EAR studies in sensitive contexts. $^{1824}$ Our study confirms that the EAR methodology works well with child participants within a wide age range, from 3 to 16 year-olds, and provides valuable findings regarding real-life interactions that cannot be captured by questionnaires, interviews or lab observations.

A key finding of the study is the amount of spontaneous injury talk in children's daily life. Forty-six minutes is similar to what is called a 'therapy hour' for psychotherapists ( $45 \mathrm{~min}) .{ }^{40}$ While therapy typically takes place once a week, this injury talk at home occurred across multiple days, for most families. Even though spontaneous talk is not the same as systematic, structured therapy, this result reinforces the notion that the family context provides a powerful opportunity to support children in the aftermath of injury, and raises questions about how parents might be engaged more proactively in providing this support.

A number of other findings are of note. First, families differed substantially in how much they talked about a child's injury; ranging from $0 \%$ to $65 \%$ of a child's interactions, and from $0 \%$ to $26 \%$ of a child's wake time. What brings about this large variation? Intuitively, one might expect children and parents to show different communication styles across ages and situations. However, the amount of injury talk was not related to injury severity nor child demographics. It is likely that such parental tailoring of conversations is reflected in more subtle aspects of the conversation, such as word choice and coherence, ${ }^{41}$ rather than the overall amount of injury talk. In the current study, we did not explore the reasons for talking or not talking about the injury with the families. ${ }^{42}$ To address this, an interesting future direction for EAR research might be to provide families with insight in their individual interaction patterns and elicit thoughts about 'the how and why' of their conversations.

Second, our findings suggest that there are considerable differences between fathers and mothers in how they support their children postinjury, even when both are at home and - in principle - have the same opportunity to talk about the injury. Mothers spoke more often with their children in general, and about the injury. Furthermore, mothers used a more positive tone when speaking with their children about the injury compared with fathers. Previous reminiscing studies ${ }^{43}{ }^{44}$ suggest no 
Table 5 Spearman's correlations with child's socioemotional functioning at 6 weeks

\begin{tabular}{|c|c|c|c|c|c|c|}
\hline Variable & $\begin{array}{l}\text { SDQ emotional } \\
\text { problems }\end{array}$ & $\begin{array}{l}\text { SDO conduct } \\
\text { problems }\end{array}$ & $\begin{array}{l}\text { SDO } \\
\text { hyperactivity }\end{array}$ & $\begin{array}{l}\text { SDO peer } \\
\text { problems }\end{array}$ & $\begin{array}{l}\text { SDQ prosocial } \\
\text { behaviour }\end{array}$ & SDO total \\
\hline Injury talk & 0.12 & 0.07 & 0.02 & 0.08 & 0.22 & 0.07 \\
\hline Direct injury talk & 0.02 & 0.03 & 0.12 & 0.01 & 0.19 & 0.03 \\
\hline Indirect injury talk & 0.11 & 0.05 & -0.04 & 0.12 & 0.19 & 0.06 \\
\hline Total injury talk with mother & 0.02 & -0.09 & 0.07 & 0.01 & 0.24 & -0.04 \\
\hline Direct injury talk with mother & -0.02 & -0.13 & 0.14 & -0.02 & $0.26^{*}$ & -0.05 \\
\hline Total injury talk with father & -0.12 & -0.15 & -0.07 & -0.03 & 0.24 & -0.16 \\
\hline Direct injury talk with father & -0.14 & -0.05 & 0.03 & -0.11 & $0.27^{*}$ & -0.14 \\
\hline Indirect injury talk with father & -0.14 & -0.19 & -0.08 & -0.02 & 0.13 & -0.17 \\
\hline Overall injury talk tone & -0.10 & -0.03 & -0.12 & 0.11 & 0.20 & -0.07 \\
\hline Mother injury talk tone & -0.26 & -0.15 & -0.12 & -0.19 & 0.19 & -0.25 \\
\hline
\end{tabular}

$\mathrm{n}=60$.

${ }^{*} p<0.05$, injury talk presented as percentage of wake time.

SDQ, Strengths and Difficulties Questionnaire.

substantial differences between fathers and mothers but considerable differences in conversations with sons versus daughters, our spontaneous injury talk data suggest an opposite pattern: no substantial differences according to the sex of the child, but sizeable differences between fathers and mothers. Possibly, mothers start such conversations more often than fathers, or children initiate them more often with their mothers than with their fathers. This would be worthwhile to explore in more depth in future studies

Regarding the relationships between injury talk characteristics and children's socioemotional functioning at 6 weeks and 3 months, we did not find a consistent set of strong associations indicating an overall pattern. Rather, we found many non-significant correlations, with a few exceptions. One explanation is that there simply is no connection of note, and parent-child conversations are not a major factor in children's psychological recovery. While this is a possibility, we consider it unlikely and certainly too premature a conclusion, considering the strength of the evidence regarding therapeutic interventions involving trauma processing, ${ }^{45}$ emotion socialisation ${ }^{7}$ and the effects of parental modelling of avoidance on child anxiety. ${ }^{46}$ Another explanation is that the relationships of importance are more subtle than could be captured by the current protocol, and that certain tendencies may cancel each other out in the correlations that we measured. For example, some children might not benefit from injury talk (eg, because they do not have substantial stress symptoms in the first place) while others might (eg, because they are avoiding reminders of what happened, and would benefit from the exposure to narratives about the experience). The 'fever model' of disclosure proposes that, much like fever, which indicates both the presence of an illness and an ongoing recovery process, trauma talk can reflect an ongoing, unresolved disturbance and an active restorative process. ${ }^{47}$ This is also in line with notion of 'efforts after meaning', the occurrence of longer narratives with more cognition and emotion words after stressful events compared with pleasant events. ${ }^{7}$ We hope that larger, in-depth studies will be able to push the boundaries of this knowledge.

Although there was no overwhelmingly clear pattern regarding the associations between injury talk characteristics and child's socioemotional functioning, a few interesting observations can be made. To start with, direct injury talk was related to emotional well-being at 3 months. To the extent that discussions helped children to make meaning of their experiences, process their emotions and consider coping strategies, ${ }^{37}$ then talking more about what happened may have fostered children's

Table 6 Spearman's correlations with child's socioemotional functioning at 3 months

\begin{tabular}{|c|c|c|c|c|c|c|}
\hline Variable & $\begin{array}{l}\text { SD0 emotional } \\
\text { problems }\end{array}$ & $\begin{array}{l}\text { SDQ conduct } \\
\text { problems }\end{array}$ & $\begin{array}{l}\text { SD0 } \\
\text { hyperactivity }\end{array}$ & $\begin{array}{l}\text { SDO peer } \\
\text { problems }\end{array}$ & $\begin{array}{l}\text { SD0 prosocial } \\
\text { behaviour }\end{array}$ & SDO total \\
\hline Injury talk & -0.20 & -0.06 & -0.20 & $-0.51^{*}$ & 0.06 & -0.29 \\
\hline Direct injury talk & $-0.36^{*}$ & 0.07 & -0.26 & $-0.38^{*}$ & -0.01 & -0.31 \\
\hline Indirect injury talk & -0.15 & -0.15 & -0.17 & $-0.55^{*}$ & 0.09 & -0.29 \\
\hline Total injury talk with mother & -0.03 & -0.18 & -0.29 & $-0.40^{*}$ & 0.23 & -0.29 \\
\hline Direct injury talk with mother & -0.06 & -0.18 & -0.30 & -0.22 & 0.18 & -0.28 \\
\hline Total injury talk with father & -0.18 & $-0.44^{*}$ & -0.23 & -0.18 & $0.37^{*}$ & -0.33 \\
\hline Direct injury talk with father & -0.26 & -0.34 & -0.31 & -0.14 & 0.31 & -0.33 \\
\hline Indirect injury talk with father & -0.13 & $-0.50^{*}$ & -0.14 & -0.19 & 0.32 & -0.30 \\
\hline Overall tone & -0.16 & 0.07 & -0.19 & -0.06 & 0.23 & -0.15 \\
\hline Mother tone & 0.09 & -0.16 & -0.21 & -0.25 & $0.56^{*}$ & -0.17 \\
\hline
\end{tabular}

$\mathrm{n}=32$.

${ }^{*} \mathrm{p}<0.05$, injury talk presented as percentage of wake time.

SDQ, Strengths and Difficulties Questionnaire. 
emotional recovery. If this was the case, there might be value in instructing parents about helpful ways to directly talk about the injury and its cause. Of course, cause-effect relationships cannot be concluded due to the non-experimental design. In any case, our findings appear to stand in contrast to the oft-held lay belief that talking about a distressing event may further distress or harm children ${ }^{42}$; where correlations were significant, these rather indicated support for the benefits of trauma talk. These and the other significant associations with greater frequency of injury talk, such as lower levels of conduct problems and higher levels of prosocial behaviour, would benefit from replication and more in-depth exploration of the possible mechanisms at play.

Interestingly, the associations between injury talk and child's socioemotional functioning, for example, the total score on the SDQ, were stronger for 3-month outcomes than for 6-week outcomes. This is in line with earlier observations that, in the first few weeks post-traumatic experience, there is little differentiation between those who have transient distress and those who will experience persistent symptoms, which led to the recommendation of 'watchful waiting' before starting interventions. ${ }^{48}$ Future studies might benefit from taking a longer time frame, for example, doing follow-up measures at 6 months, since at that point spontaneous remission of post-traumatic stress seems infrequent. ${ }^{49}$

The EAR methodology allowed us to generate and analyse data that are novel for the domain of mental health in general and the emerging field of behavioural psychotraumatology in particular. Due to its sampling approach, the method makes it possible to study nuanced behaviours and conduct fine-grained analyses regarding substantial numbers of participating families. While our study is innovative in assessing subtle behaviour in daily life after trauma, the following limitations should be taken into account. First, the sample size is still modest, precluding us from nuanced analyses and firm conclusions, also with respect to differences between the baseline sample and the follow-up samples. Second, the study is exploratory. We considered it important to show the various significant associations and lack thereof; it is therefore vital to keep in mind that this study was not hypothesis driven, and no solid conclusions can be drawn from the statistics as yet. In addition, even when there was a temporal lag in measurements (eg, between the EAR data collection and the 6-week measure), the direction of relationships is not clear for various variables. For example, it may be the case that prosocial children talk more about the injury, that injury talk increases prosocial behaviour, or that parents who talk with their children more about the injury also perceive them as more prosocial and less problematic. Again, further research is required to disentangle these possibilities. Apart from obvious limitations regarding causality, it is important to keep in mind that the sample is selective; people are cautious regarding participation in a behaviour-assessment project in their own home, and we invited only English-speaking families in order to make transcription and coding feasible. It would be valuable to include a control group in future research (eg, children experiencing no or other types of transition in life).

\section{CLINICAL IMPLICATIONS}

This study reported the first insights from the Ear for Recovery project. The EAR provided a snapshot of daily life after the injury that could not have been otherwise obtained through questionnaires or laboratory observation. Our results offer hints at what may aid psychological recovery in children postinjury, such as direct injury talk, and demonstrated the basic feasibility of using the EAR with families post-trauma. Although our study design prevents conclusions about causal relationships, the EAR offers new opportunities for research data collection regarding mental health, and it may also be further developed as a tool for mental health professionals and families wishing to get a better understanding of daily family interactions.

Acknowledgements We would like to thank all the participating families, medical and research staff, and students involved. In particular, we would like to thank
Kelly Rentscher, Laura Abbey, Naile Alangor, Caitlin Arthur, Hayley Ayton, Caitlin Bishop, Peter Bowles, Prue Dunstan, Shanti Gangatharan, Claire Hoysted, Georgina Johnstone, Maggie Lam, Jasmine Loo, Deborah Lewis, Scott McDonald, Cameron Palmer, Julia Polak and Claire Wilkin.

Funding This project has been supported by the Netherlands Organisation for Scientific Research (Rubicon Fellowship \#446-11-021); the National Health and Medical Research Council, Australia (Early Career Fellowship \#1090229 and Centre of Research Excellence for Paediatric Emergency Medicine); Monash University (Larkins program); the Australian Government Research Training Program Scholarship; the Victorian Government's Operational Infrastructure Support Program; and Royal Children's Hospital Foundation, Melbourne.

\section{Competing interests None declared.}

Ethics approval The study has been approved by the Human Research Ethics Committee of the Royal Children's Hospital Melbourne (study number 33103) and the Monash University Human Research Ethics Committee (file number CF13/25152013001322).

Provenance and peer review Not commissioned; externally peer reviewed.

\section{(6) OPEN ACCESS}

Open Access This is an Open Access article distributed in accordance with the Creative Commons Attribution Non Commercial (CC BY-NC 4.0) license, which permits others to distribute, remix, adapt, build upon this work non-commercially, and license their derivative works on different terms, provided the original work is properly cited and the use is non-commercial. See: http://creativecommons.org/licenses/ by-nc/4.0/

- Additional material is published online only. To view please visit the journal online (http://dx.doi.org/10.1136/eb-2017-102736)

EA and $S G$ contributed equally.

doi:10.1136/eb-2017-102736

Received 27 May 2017; Revised 21 September 2017; Accepted 6 October 2017

\section{REFERENCES}

1. Carrion VG, Weems CF, Ray R, et al. Toward an empirical definition of pediatric PTSD: the phenomenology of PTSD symptoms in youth. J Am Acad Child Adolesc Psychiatry 2002;41:166-73

2. Price J, Kassam-Adams N, Alderfer MA, et al. Systematic review: A reevaluation and update of the integrative (trajectory) model of pediatric medical traumatic stress. $J$ Pediatr Psychol 2016;41:86-97.

3. Salmon K, Bryant RA. Posttraumatic stress disorder in children. The influence of developmental factors. Clin Psychol Rev 2002;22:163-88.

4. Marsac ML, Donlon KA, Winston FK, et al. Child coping, parent coping assistance, and post-traumatic stress following paediatric physical injury. Child Care Health Dev 2013;39:171-7.

5. Marsac ML, Mirman JH, Kohser KL, et al. Child coping and parent coping assistance during the peritrauma period in injured children. Fam Syst Health 2011;29:279-90.

6. Ackil JK, Van Abbema DL, Bauer PJ. After the storm: enduring differences in mother-child recollections of traumatic and nontraumatic events. J Exp Child Psychol 2003;84:286-309.

7. Fivush R, McDermott Sales J, Bohanek JG. Meaning making in mothers' and children's narratives of emotional events. Memory 2008;16:579-94.

8. Marsac ML, Kassam-Adams N. A novel adaptation of a parent-child observational assessment tool for appraisals and coping in children exposed to acute trauma. Eur $\mathrm{J}$ Psychotraumatol 2016;7:31879.

9. Laible DJ. Mother-child discourse surrounding a child's past behavior at 30 months Links to emotional understanding and early conscience development at 36 months. Merrill-Palmer Quarterly 2004;50:159-80.

10. Sales JM, Fivush R. Social and emotional functions of mother-child reminiscing about stressful events. Soc Cogn 2005;23:70-90.

11. Bauer PJ, Stark EN, Lukowski AF, et al. Working together to make sense of the past: Mothers' and children's use of internal states language in conversations about traumatic and nontraumatic events. J Cogn Dev 2005;6:463-88.

12. Peterson C, Biggs M. Stitches and casts: Emotionality and narrative coherence. Narrative Inquiry 1998;8:51-76.

13. Sales JM, Fivush R, Peterson C. Parental reminiscing about positive and negative events. J Cogn Dev 2003;4:185-209. 
14. Mehl MR, Pennebaker JW, Crow DM, et al. The Electronically Activated Recorder (EAR): a device for sampling naturalistic daily activities and conversations. Behav Res Methods Instrum Comput 2001;33:517-23.

15. Mehl MR, Robbins ML, Deters FG. Naturalistic observation of health-relevant social processes: the electronically activated recorder methodology in psychosomatics. Psychosom Med 2012;74:410-7.

16. Alisic E, Barrett A, Bowles P, et al. Ear for recovery: protocol for a prospective study on parent-child communication and psychological recovery after paediatric injury. $B M J$ Open 2015;5:e007393.

17. Mehl MR. The Electronically Activated Recorder (EAR): a method for the naturalistic observation of daily social behavior. Curr Dir Psychol Sci 2017;26:184-90.

18. Robbins ML, López AM, Weihs KL, et al. Cancer conversations in context: naturalistic observation of couples coping with breast cancer. J Fam Psychol 2014;28:380-90.

19. MehI MR, Pennebaker JW. The social dynamics of a cultural upheaval: social interactions surrounding September 11, 2001. Psycho/ Sci 2001;14:579-85.

20. Imami L, Tobin ET, Kane HS, et al. Effects of socioeconomic status on maternal and child positive behaviors in daily life among youth with asthma. J Pediatr Psychol 2015;40:55-65.

21. Slatcher RB, Robles TF. Preschoolers' everyday conflict at home and diurnal cortisol patterns. Health Psychol 2012;31:834.

22. Slatcher RB, Trentacosta CJ. A naturalistic observation study of the links between parental depressive symptoms and preschoolers' behaviors in everyday life. J Fam Psychol 2011;25:444.

23. Slatcher RB, Trentacosta CJ. Influences of parent and child negative emotionality on young children's everyday behaviors. Emotion 2012;12:932.

24. Tobin ET, Kane HS, Saleh DJ, et al. Naturalistically observed conflict and youth asthma symptoms. Health Psychol 2015;34:622-31.

25. Alisic E, Barrett A, Bowles P, et al. Topical Review: Families Coping With Child Trauma: A Naturalistic Observation Methodology. J Pediatr Psychol 2016;41:117-27.

26. Teasdale G, Jennett B. Assessment of coma and impaired consciousness. A practical scale. Lancet 1974;2:81-4.

27. Coakley RM, Forbes PW, Kelley SD, et al. Family functioning and posttraumatic stress symptoms in youth and their parents after unintentional pediatric injury. J Trauma Stress 2010;23:807-10.

28. Australian Bureau of Statistics. Census of Population and Housing: SocioEconomic Indexes for Areas (SEIFA), Australia, 2011 (2033.0.55.001), 2013. www. abs.gov.au/ausstats/abs@.nsf/Lookup/2033.0.55.001main+features100052011.

29. Gennarelli TA, Wodzin E. AIS 2005: a contemporary injury scale. Injury 2006;37:1083-91.

30. Bolorunduro OB, Villegas C, Oyetunji TA, et al. Validating the Injury Severity Score (ISS) in different populations: ISS predicts mortality better among Hispanics and females. J Surg Res 2011;166:40-4.
31. Goodman A, Goodman R. Strengths and difficulties questionnaire as a dimensional measure of child mental health. J Am Acad Child Adolesc Psychiatry 2009;48:400-3.

32. Becker A, Woerner W, Hasselhorn M, et al. Validation of the parent and teacher SDO in a clinical sample. Eur Child Adolesc Psychiatry 2004;13:ii11-6.

33. Children and War Foundation. Children's Revised Impact of Event Scale (CRIES-13), 2005. http://www.childrenandwar.org/measures/children\%E2\%80\%99s-revisedimpact-of-event-scale-8-\%E2\%80\%93-cries-8/ies13/ (accessed 29 Jul 2014).

34. Foa EB, Johnson KM, Feeny NC, et al. The child PTSD Symptom Scale: a preliminary examination of its psychometric properties. J Clin Child Psychol 2001;30:376-84.

35. MehI MR, Holleran SE. An empirical analysis of the obtrusiveness of and participants' compliance with the Electronically Activated Recorder (EAR). Eur J Psychol Assess 2007;23:248-57.

36. Mehl MR, Vazire S, Ramírez-Esparza N, et al. Are women really more talkative than men? Science 2007;317:82.

37. Cohen $\mathbf{P}$, Cohen J, Aiken LS, et al. The problem of units and the circumstance for POMP. Multivariate Behav Res 1999;34:315-46.

38. Hills AM. Foolproof guide to statistics using IBM SPSS. Pearson Education Australia, 2011.

39. de Winter JC, Gosling SD, Potter J. Comparing the pearson and spearman correlation coefficients across distributions and sample sizes: A tutorial using simulations and empirical data. Psychol Methods 2016;21:273.

40. Sandberg LS. The 45-Minute Therapy'Hour': a Sign of the Times? New York: New York Times, 2013.

41. Fivush R. Maternal reminiscing style and children's developing understanding of self and emotion. Clin Soc Work J 2007;35:37-46.

42. Barnes J, Kroll L, Burke 0, et al. Qualitative interview study of communication between parents and children about maternal breast cancer. BMJ 2000;321:479-82.

43. Adams S, Kuebli J, Boyle PA, et al. Gender differences in parent-child conversations about past emotions: a longitudinal investigation. Sex Roles 1995;33:309-23.

44. Reese E, Fivush R. Parental styles of talking about the past. Dev Psychol 1993;29:596.

45. Foa EB, Keane TM, Friedman MJ, et al. Effective treatments for PTSD: practice guidelines from the International Society for Traumatic Stress Studies. Guilford Press, 2008.

46. Dadds MR, Barrett PM, Rapee RM, et al. Family process and child anxiety and aggression: an observational analysis. J Abnorm Child Psychol 1996;24:715-34.

47. Stiles WB, Shuster PL, Harrigan JA. Disclosure and anxiety: a test of the fever model. J Pers Soc Psychol 1992;63:980.

48. National Institute for Health and Clinical Excellence. Posttraumatic stress disorder: management. NICE guideline (CG26), 2005.

49. Hiller RM, Meiser-Stedman R, Fearon P, et al. Research Review: Changes in the prevalence and symptom severity of child post-traumatic stress disorder in the year following trauma: a meta-analytic study. J Child Psychol Psychiatry 2016;57:884-98. 